\title{
Research on Financial Risk Early Warning of Listed Companies on the Science and Technology Innovation Board Based on the Life Cycle Perspective
}

\author{
Lan Wang ${ }^{1}$, Yilin Xiong ${ }^{2 *}$
}

\author{
${ }^{1}$ Xi'an University of Science and Technology \\ ${ }^{2}$ Xi'an University of Science and Technology \\ *Corresponding author: Xiong Yilin. Email: 395291373@qq.com
}

\begin{abstract}
This paper selects the 2017 to 2019 science and technology innovation board listed companies and ST companies as samples, from finance, corporate governance and life cycle three categories to construct and optimize the financial risk early warning index system. Factor analysis method and binary logistic regression method are used to construct the financial early warning models of listed companies in the science and technology innovation board in the growth and maturity periods, and then tested. It is found that the accuracy of the early-warning model in the growth stage can reach $90 \%$, and the accuracy of the early-warning model in the growth stage can reach $95 \%$.
\end{abstract}

Keywords: Financial early warning, Logistic regression analysis, Financial risk management, Listed company on science and technology innovation board

\section{INTRODUCTION}

With the in-depth implementation of the registration system of science and technology innovation board in China, due to the low barriers to market entry, the types and number of listed companies are also rising sharply. As of December 31, 2020, 214 listed companies have been officially registered on the science and technology innovation board in just two years. In such a market environment, some companies cannot balance the relationship between development and financial results, the root cause is that many production and operation activities are dragged down by the backward level of financial management. If we want to remain invincible in the fierce market competition and complex business environment, we must improve the level of financial management and fully implement the work of financial risk early warning.

According to the enterprise life cycle theory, the life cycle of an enterprise generally includes four stages: the introduction period, the growth period, the maturity period and the decline period, and the causes and manifestations of financial risks in each stage are different[1]. Most of the listed companies in the science and technology innovation board are in the early stage of starting their own business, and their risks include research and development failure, capital chain rupture and other problems. After entering the growth period, the company begins to make profits, the capital chain tends to be stable, and the company has a certain social network. The risks are manifested as diversified "traps" such as complex business. After entering the mature period where the growth rate slows down but the profit rate increases rapidly, the risk manifests itself in difficulties such as insufficient innovation ability or improper transformation. The most significant risk performance in the recession is the lack of capital chain. If the enterprise can accurately position itself, it may "regain new life".

This paper constructs and optimizes the financial risk early warning index system from the three categories of finance, corporate governance and life cycle, constructs the financial early warning model of the listed companies in the science and technology innovation board in the growth and maturity stages by using factor analysis method and binary logistic regression method, and tests it to provide ideas for the financial early warning. 


\section{MODEL DESIGN AND INDEX SYSTEM ONSTRUCTION}

\subsection{Model design}

In this paper, the binary Logistic regression method is used to establish the financial crisis early warning model. As a nonlinear model, the Logistic model is a forecasting method in which the most commonly used predictive explanatory variables are dichotomous variables[2]. In this paper, Y value of sample enterprises with financial crisis is set as 1 , and $\mathrm{Y}$ value of normal enterprises is set as 0 . In other words, the closer the $\mathrm{Y}$ value is to 1 , the more likely the enterprise is to have financial crisis; the closer the $\mathrm{Y}$ value is to 0 , the healthier the enterprise is. Logistic hypothesis shows the following relationship between the occurrence probability of the dependent variable and the independent variable that affects its occurrence:

$$
\begin{gathered}
P_{i}=F\left(K_{i}\right)=1 /\left(1+e^{-\kappa i}\right) \\
K_{i}=a_{0}+a_{1} X_{1}+a_{2} X_{2}+\cdots+a_{n} X_{n}
\end{gathered}
$$

$P_{i}$-Even some probability;

$K_{i}$-interaction of the selected factors;

$X_{i}$-independent variables.

The linear regression model is: . .

$$
\operatorname{Ln}\left(\frac{p^{\prime}}{1-p^{\prime}}\right)=a_{0} X_{0}+a_{1} X_{1}+a_{2} X_{2}+\cdots+a_{n} X_{n}
$$

The selection ratio between the ST/*ST sample and the healthy sample in this paper is $3: 1$, so the cut value selected according to the existing papers is $0.75, \ln (\mathrm{p} /(1-$ $\mathrm{p})$ )=Yi. When the Yi value of the analyzed object is greater than 0.75 , it will be considered as having financial crisis, while when the $\mathrm{Yi}$ value is less than 0.75 , it will be considered that the possibility of financial crisis is low or no financial crisis.

\subsection{Construction of financial early warning index system}

For those listed companies on the science and technology innovation board that have reduced listing requirements, the hidden trouble is prominent. The reduction of profitability requirements on the science and innovation board may make some enterprises manipulate profits to meet the listing standards. The science and technology innovation board enterprises and the main board enterprises will face the same problems of corporate governance, improper corporate governance system will also accelerate the delisting of enterprises. In addition, each life cycle has different characteristics of financial management and financial risk.

Based on this, appropriate indicators are designed from three dimensions of finance, corporate governance and life cycle to form a "three-dimensional" risk indicator framework of science and technology innovation board. It mainly includes (1) financial risks. Mainly including solvency, profitability, operating capacity and growth capacity; (2) Corporate governance risks. (3) Lifecycle

\begin{tabular}{|c|c|c|c|c|}
\hline $\begin{array}{c}\text { Indicator } \\
\text { s } \\
\text { dimensio } \\
n\end{array}$ & & The index name & $\begin{array}{l}\text { variabl } \\
\quad \mathrm{e}\end{array}$ & Variable meaning \\
\hline \multirow{12}{*}{$\begin{array}{c}\text { Financial } \\
\text { risk } \\
\text { solvency }\end{array}$} & \multirow{6}{*}{$\begin{array}{l}\text { Debt } \\
\text { paying } \\
\text { ability }\end{array}$} & Current ratio & $\mathrm{X} 1$ & Current assets/current liabilities \\
\hline & & Quick ratio & X2 & $\begin{array}{c}\text { (current assets - inventory)/ current } \\
\text { liabilities }\end{array}$ \\
\hline & & Cash ratio & $\mathrm{X3}$ & Monetary funds/current liabilities \\
\hline & & Asset-liability ratio & $\mathrm{X} 4$ & Total liabilities/total assets \\
\hline & & Cash to maturity debt ratio & $\times 5$ & $\begin{array}{l}\text { Total net cash flow from } \\
\text { operations/total liabilities }\end{array}$ \\
\hline & & Working capital ratio & $x 6$ & $\begin{array}{c}\text { (undistributed profit+surplus reserves)/ } \\
\text { total assets }\end{array}$ \\
\hline & \multirow{4}{*}{$\begin{array}{l}\text { profitabil } \\
\text { ity }\end{array}$} & Return on equity & $\mathrm{X} 7$ & Net Income/Average Net Assets \\
\hline & & Rate of return on total assets & X8 & $\begin{array}{c}\text { (total profit + finance expense)/average } \\
\text { total assets }\end{array}$ \\
\hline & & Net interest rate on total assets & X9 & $\begin{array}{l}\text { Net interest rate on total assets = net } \\
\text { profit/average balance of total assets }\end{array}$ \\
\hline & & Sales margin & $\mathrm{X} 10$ & Operating profit/revenue \\
\hline & \multirow{2}{*}{$\begin{array}{l}\text { Operatio } \\
\text { n ability }\end{array}$} & Accounts receivable turnover & $\mathrm{X} 11$ & $\begin{array}{c}\text { Main business revenue/average } \\
\text { accounts receivable }\end{array}$ \\
\hline & & Inventory turnover & $\mathrm{X} 12$ & $\begin{array}{l}\text { The main operating cost/average } \\
\text { inventory balance }\end{array}$ \\
\hline
\end{tabular}
characteristics. See table 1.

Table 1. Initial indicators 


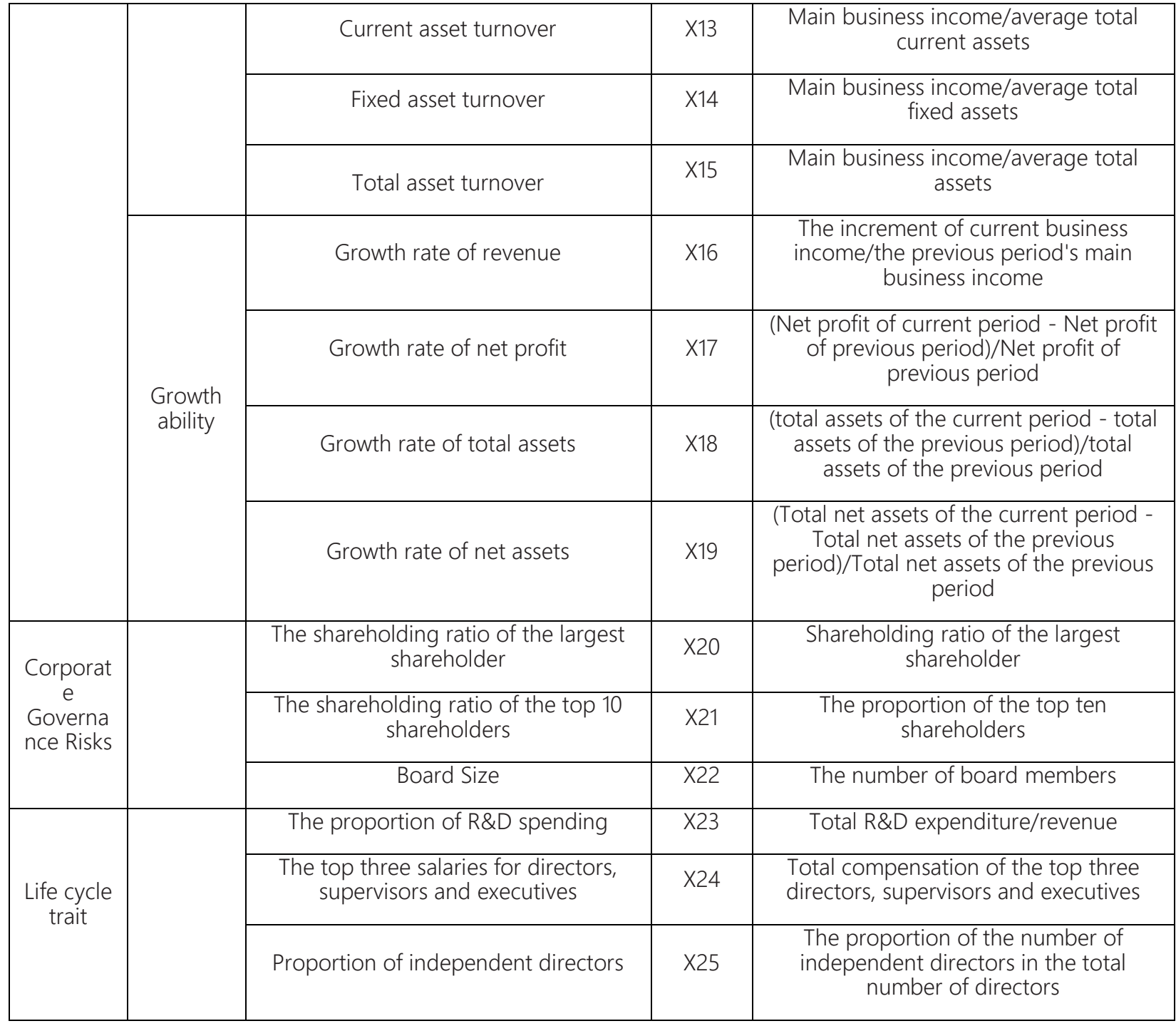

\section{RESEARCH DESIGN}

\subsection{Sample selection and data source}

The data studied in this paper follow the principle of data availability. The end point of the observation period was set on December 31,2019, and the observation years were 2017-2019. Three years of data were selected for the study. The empirical data in this paper are collected from the CSMAR China Financial and Economic Database, Wind financial terminal and part of manual collection. Select company nearly three years of financial indicators, to expand the sample vertical depth, select three years sample build model is helpful to find the potential risk as soon as possible, thus for managers in time and control time[3]

\subsection{Financial crisis standard setting}

Crisis group for sample selection: the listed company was noted "ST" is due to there was a problem in enterprise financial situation by special processing, rather than the other non-financial reasons, because the financial situation is special processing refers to: according to the relevant accounting evaluation audit identified the special processing and nearly a year to less than shareholders registered capital.

\subsection{Enterprise lifecycle demarcation}

In this paper, the cash flow method of Dickinson[4] is adopted to conduct preliminary screening of listed companies on the science and technology innovation board. Finally, $10 \mathrm{ST}$ and *ST companies in the data growth period and 30 health companies in the science and technology innovation board were selected, and a total of 120 samples were collected in three years. In the mature stage, there are $7 \mathrm{ST}$ and *ST companies and 21 health companies on the science and technology innovation board, with a total of 84 samples in three years. There were too few samples in the recession period for regression analysis, so they were eliminated. 


\subsection{Key risk indicator screening}

Since not every basic indicator has a good degree of differentiation, this paper first conducted normality test and significance test through the K-S test method of
SPSS software and the early warning indicators in Table 1 of Mann-Whitney $U$ test, eliminated the evaluation indicators without significant distinguishing ability, and selected the key risk indicators in the two periods[5].

Table 2. Screening of key risk indicators of listed companies in the growth and maturity stages

\begin{tabular}{|c|c|c|}
\hline dimensionality & Growth period & mature period \\
\hline Financial risk & $\begin{array}{c}\text { X1、X2、X3、X4、X5、X6、X7、X8、X9、 } \\
\text { X10、X14、X15、X16、X17、X18、X19 }\end{array}$ & $\begin{array}{l}\text { X1、X2、X3、X4、X6、X7、X8、X9、X10、 } \\
\text { X11、X13、X14、X15、X16、X17、X18、X19 }\end{array}$ \\
\hline $\begin{array}{c}\text { Corporate } \\
\text { Risks }\end{array}$ & X20、X21 & X21、X22 \\
\hline Life cycle trait & X23 & X25 \\
\hline
\end{tabular}

\subsection{Key risk index extraction}

Since multicollinearity will seriously affect the prediction ability of survival analysis model, this paper chose principal component analysis to further optimize the index system (see Table 3).

Table 3. Key index of scientific risk in growth and maturity period

\begin{tabular}{|l|l|l|}
\hline \multirow{5}{*}{ Key risk index extraction } & \multicolumn{1}{|c|}{ Growth period } & \multicolumn{1}{|c|}{ mature period } \\
\cline { 2 - 3 } & F1 Short-term solvency & F1 Debt paying ability \\
\cline { 2 - 3 } & \multirow{5}{*}{ F3 Growth ability } & F2 profitability \\
\cline { 2 - 3 } & F4 Debt paying ability & \multirow{2}{*}{ F3 Growth ability } \\
\cline { 2 - 3 } & F5 Operation ability & F4 Corporate governance \\
\cline { 2 - 3 } & F6 Degree of ownership concentration & F6 Operation ability \\
\cline { 2 - 3 } & F7 Cash flow solvency & \\
\hline
\end{tabular}

\section{THE EMPIRICAL ANALYSIS}

\subsection{The construction of financial risk model in growth period}

A total of 120 samples were collected from 10 ST enterprises and 30 healthy enterprises on the science and technology innovation board identified in the previous paper. Regressive analysis was conducted on the 7 principal components extracted in Table 3 to build a Logistic early warning model in the growth period. See Table 4 for details.

Table 4. Assessment results of growth period model of listed companies on science and technology innovation board

\begin{tabular}{|c|c|c|c|c|c|c|c|}
\hline \multicolumn{2}{|l|}{} & B & S.E, & Wals & df & Sig. & Exp (B) \\
\hline Step 1 & F1 & -0.306 & 0.368 & 0.694 & 1 & 0.405 & 0.736 \\
\hline
\end{tabular}




\begin{tabular}{|c|c|c|c|c|c|c|c|}
\hline & F2 & 1.429 & 0.697 & 4.210 & 1 & 0.040 & 4.176 \\
\cline { 2 - 8 } & F3 & -0.652 & 0.262 & 6.197 & 1 & 0.013 & 0.521 \\
\cline { 2 - 8 } & F4 & -2.541 & 0.591 & 18.489 & 1 & 0.000 & 0.079 \\
\cline { 2 - 8 } & F5 & -0.875 & 0.383 & 5.231 & 1 & 0.022 & 0.417 \\
\cline { 2 - 8 } & 1.439 & 0.408 & 12.467 & 1 & 0.000 & 4.218 \\
\hline
\end{tabular}

From Table 4, we can get the financial crisis early warning model of listed companies in the growth period of science and technology innovation board(4):

$$
\begin{gathered}
\operatorname{Logit}(Y)=-2.034-0.306 F_{1}+1.429 F_{2}-0.652 F_{3} \\
-2.541 F_{4}-0.875 F_{5}+1.439 F_{6}+0.043 F_{7}
\end{gathered}
$$

\subsection{The construction of financial risk model in mature period}

Table 5. Assessment results of the mature stage model of listed companies on the Science and Technology Innovation Board

\begin{tabular}{|c|c|c|c|c|c|c|c|}
\hline \multicolumn{2}{|c|}{} & B & S.E, & Wals & df & Sig. & Exp (B) \\
\hline \multirow{4}{*}{} & F1 & -1.939 & 0.686 & 7.984 & 1 & 0.005 & 0.144 \\
\cline { 2 - 8 } & F2 & -3.062 & 1.026 & 8.902 & 1 & 0.003 & 0.047 \\
\cline { 2 - 8 } & F3 & -3.610 & 1.386 & 6.789 & 1 & 0.009 & 0.027 \\
\cline { 2 - 8 } & F4 & 2.832 & 1.017 & 7.755 & 1 & 0.005 & 16.979 \\
\cline { 2 - 8 } & F5 & -1.545 & 1.368 & 1.276 & 1 & 0.259 & 0.213 \\
\cline { 2 - 8 } & F6 & -8.233 & 3.093 & 7.083 & 1 & 0.008 & 0.000 \\
\cline { 2 - 8 } & Constant & -6.088 & 1.932 & 9.934 & 1 & 0.002 & 0.002 \\
\hline
\end{tabular}

According to Table 5, the financial crisis early warning model of listed companies in the mature period
The $7 \mathrm{ST}$ enterprises identified in the previous paper and the 21 healthy enterprises on the science and technology innovation board that are paired with them are 84 samples in three years. Regressive analysis is conducted on the 6 principal components extracted in Table 3 to construct the Logistic early warning model in the mature stage. See Table 5 below for details

$$
\begin{aligned}
\operatorname{Logit}(Y) & =-6.088-1.939 F_{1}-3.062 F_{2}-3.610 F_{3} \\
& +2.832 F_{4}-1.545 F_{5}-8.233 F_{6}
\end{aligned}
$$

It can be seen from Model 5 that F1, F2, F3, F5 and F6 are negatively correlated with the occurrence of financial crisis, that is, the stronger the profitability, debt paying ability, operation and growth ability of the listed company, the less likely it is to have financial crisis. F4 is positively correlated with the occurrence of financial crisis, that is, the better the corporate governance is, the more likely financial crisis is to occur. of science and technology innovation board can be obtained (5):

\subsection{Results of inspection}

In addition to the research samples of the Science and Technology Innovation Board in 2019, 15 healthy companies in the growth stage and mature stage, and 5 companies in crisis stage were selected as the test group samples and substituted into the model. The results are shown in Table 6. 
Table 6. The early warning model results of the test group in the growth and maturity stages

\begin{tabular}{|c|c|c|c|c|c|c|c|c|}
\hline & \multirow{3}{*}{\multicolumn{2}{|c|}{ Observed }} & \multicolumn{3}{|c|}{ Growth period } & \multicolumn{3}{|c|}{ mature period } \\
\hline & & & \multicolumn{2}{|c|}{ Whether the ST } & \multirow{2}{*}{$\begin{array}{l}\text { Percentage } \\
\text { Correct }\end{array}$} & \multicolumn{2}{|c|}{ Whether the ST } & \multirow{2}{*}{$\begin{array}{c}\text { Percentage } \\
\text { Correct }\end{array}$} \\
\hline & & & 0 & 1 & & 0 & 1 & \\
\hline \multirow{3}{*}{ Step 1} & \multirow{2}{*}{$\begin{array}{c}\text { Whether } \\
\text { the ST }\end{array}$} & 0 & 13 & 2 & 86.67 & 15 & 0 & 100.00 \\
\hline & & 1 & 0 & 5 & 100.00 & 1 & 4 & 80.00 \\
\hline & \multicolumn{2}{|c|}{ Overall Percentage } & & & 90.00 & & & 95.00 \\
\hline
\end{tabular}

When the $\mathrm{P}$ value is greater than 0.75 , it is identified as an enterprise in financial crisis; otherwise, when the $\mathrm{P}$ value is less than or equal to 0.75 , it is identified as a financially healthy enterprise. As can be seen from Table 6,13 healthy companies in the growth stage have accurate predictions, with an accuracy rate of $86.67 \%$. Five of the crisis companies had accurate predictions, with an accuracy rate of $100 \%$ and an overall accuracy rate of $90 \%$. The prediction accuracy of healthy companies in mature period is $100 \%$, the accuracy of crisis companies is $80 \%$, and the overall accuracy of the model is $95 \%$, which proves that the accuracy test of the model is good.

\section{CONCLUSION}

This paper selects listed companies in the growth and maturity stages of science and technology innovation board as research samples, designs a "three-dimensional" risk index system from three categories of finance, corporate governance and life cycle, and makes a regression by combining the life cycle theory with Logistic model to construct and test different financial early warning models in the growth and maturity stages. It is concluded that the accuracy of the model in the growth period is up to $90 \%$, and that in the mature period is up to $95 \%$.

For the prevention and control of financial risks in different life cycles of the science and technology innovation board, not only the internal financial management of the company should play a main role, but also the impact of corporate governance and life cycle should be paid attention to. Specifically, for listed companies in the growth period of the science and technology innovation board, the dominant share should be avoided and the equity should be dispersed. The maximum shareholding ratio of individual stock shareholders can be set, and the debt paying ability and profitability should be paid more attention. For listed companies in the mature stage of science and technology innovation board, we should pay attention to innovation and development, avoid transformation failure, sit idle and pay more attention to profitability, growth ability and corporate governance factors.

\section{REFERENCES}

[1] J. Min, J. Y. Li. Research on financial risk assessment of small and medium sized enterprises from the perspective of life cycle - Based on survival analysis model[J]. Communication of Finance and Accounting, 2021(04):146-150.

[2] V. Dickinson. Cash flow patterns as a proxy for firm life cycle[J]. The Accounting Review, 2011(6):1969-1994.

[3] J. M. Yan, Y. L. Liu, B. Wan. Research on financial support of small and medium sized science and technology enterprises based on life cycle[J]. Communication of Finance and Accounting, 2019(17):14-16.

[4] S. Y. Wu. Financial risk assessment of core enterprises in supply chain from the perspective of life cycle[J]. Friends of Accounting, 2016(06):4447.

[5] T. Q. Mao. Three-dimensional early warning index construction of enterprise financial risk based on industry perspective $[\mathrm{J}]$. Communication of Finance and Accounting, 2018(23):14-117. 